Reviews in Digital Humanities • Vol. 2, No. 9

\title{
Review: The Mixtape Museum
}

Tanya Clement ${ }^{1}$

${ }^{1}$ University of Texas at Austin

Published on: Sep 13, 2021

DOI: $10.21428 / 3 e 88 f 64 f .724 b 63 b 8$

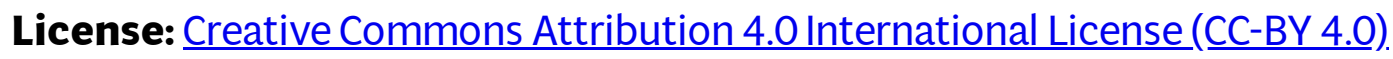




\section{Project}

The Mixtape Museum

Project Director

Regan Sommer McCoy,, Columbia University

Project URL

https://mixtapemuseum.org/

\section{Project Reviewer}

Tanya Clement, University of Texas at Austin

\section{Project Overview}

\section{Regan Sommer McCoy}

The Mixtape Museum (MXM) is an archive project dedicated to collecting, preserving, and sharing knowledge related to mixtape history. MXM advances public understanding and appreciation of the art, history, technique, and impact mixtapes have made worldwide. While encouraging research on mixtapes as records of time, place, and situation, it also examines the individuals that have shaped their existence.

While the project covers all genres, it prioritizes Hip Hop research through the mixtape lens. The compact cassette served as one of Hip Hop's earliest documents of record, playing an integral role in evolving and advancing the genre. Many of these foundational recordings have been identified but have few resources to guarantee their protection. MXM aims to support collectors in protecting their recordings and making them aware of archival best practices. This includes documenting, cataloging, and digitizing; gathering metadata; and capturing oral histories. The gathering of mixtape metadata will be pivotal in proving the impact of mixtapes, a crucial contribution often denied by the big music industry.

Central to MXM is the Mixtape Memory Collection, mapped by mixtape creators. These creators are DJs, artists, and everyday music lovers whose memories span the analog and digital eras. This multimedia collection amplifies otherwise hidden creators and ensures an array of voices are included in the historical record. To widen our reach and diversify participation from the mixtape community, we've formed

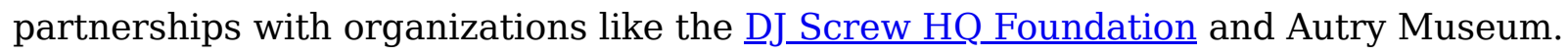


MXM encourages the academic study of mixtapes, capturing interdisciplinary scholars and researchers' attention from many disciplines, including the humanities. The MXM has been used in Stanford's Program in Writing and Rhetoric, including in the course “Freedom's Mixtape: DJing Contemporary African American Rhetorics,” and in the “Pop Music as Art and Business” course at The School of the New York Times.

The majority of MXM's activity is managed by its founder Regan Sommer McCoy, with support from a community of advisors and mentors. Support for the MXM has included the Columbia University's A'Lelia Bundles Community Scholars Program, a travel grant from the Association for Recorded Sound Collections, and the Institute for Museum and Library Services' Game Plan Grant. MXM has been featured in Columbia University_News, KCRW, and TapeOp Magazine.

\section{Project Review}

\section{Tanya Clement}

If you were a teenager in the 1980s in the United States, you made mixtapes. Before the internet went mainstream, before computers let you save things onto disc, cassette recorders let us record things on tape. Sometimes you made a mixtape by recording your favorite songs from the radio. Sometimes you made them by dubbing favorite songs from another cassette tape because you were lucky enough to have a dual cassette player. Regardless of how you made them, you made them. More often than not, they were for someone you loved with songs you loved-or for someone you were trying to get over with songs you loved together. In any case, it was a labor of love: you loved the songs. The mixtape was also the means by which some music genres, including Hip Hop and Rap, came into the mainstream scene.

The Mixtape Museum (MXM) is an archive project established to collect, preserve, and share knowledge and experiences related to this time in history when the average person first had the power to compile and share the songs they liked, in the order they liked, for a particular audience. In their own words, "Through exhibitions, technology, publications, symposia, collaborative projects, and other partnerships," the aim of $\mathrm{MXM}$, is "to create an environment that encourages dialogue between scholars, music professionals, and enthusiasts on the mixtape's various functions in society." The MXM focuses on Hip Hop since the compact cassette played a particular role in advancing the Hip Hop genre. 
MXM is devoted to advancing public understanding and appreciation of the art, history, technique, and impact mixtapes have made around the world. The advisory board is comprised of academics, artists, archivists, cinematographers, collectors, curators, documentarians, educators, historians, and librarians, making the project about the artistry of mixing as well as the importance of preserving this aspect of cultural history. In the Hip Hop genre, MXM has identified important recordings with few resources to guarantee their preservation. Consequently, MXM supports collectors in protecting their recordings by making them aware of archival best practices.

Central to these goals is MXM's Mixtape Memory_Collection, which comprises memories written by mixtape creators, including scholars, music professionals, and enthusiasts who recall making, distributing, and enjoying mixtapes during both the analog and digital eras. Contributors include gospel DJ Rock Jesus from Hampton, VA, who recalls listening to Kid Capri and Stephanie Mills blending "Something in the Way You Make Me Feel." His post includes a snippet of the blend posted to SoundCloud. Celebrating the 47th anniversary of Hip Hop, Rich Nice of the A\&R Room in New York City also posts a "a glimpse of what authentic Hip Hop music sounded like before record companies and culture vultures" in a SoundCloud snippet of the "Merry-GoRound Mix" that includes "party favorites and park jam classics that Kool Herc, Coke La Rock, Clark Kent, and Jay Cee use to play."

Photographs of DJs and boomboxes alongside images of tape covers and magazine articles are highlighted in multiple posts, including those in memory of Justo Faison, a Hip Hop promoter and founder of the only national mixtape awards, Justo's Mixtape Awards, part of a larger endeavor to bring mixtape DJs to a national audience through media such as MTV and The Source magazine. This multimedia collection of memories works to amplify songs, creators, and a movement that might otherwise remain muffled in the historical record.

The MXM is primarily a website and a blogging platform that is lightweight and easy to update and maintain by the community. Many of the contributors use SoundCloud as a platform to share mixtapes and include links to these mixtapes and explanations on MXM. This means that if the MXM is not maintained, the mixtapes can still be found on SoundCloud. However, one concern about this preservation practice might be the sustainability of SoundCloud and whether or not it will remain supported and cost effective as a free platform. Additionally, MXM uses crucial archival practices, including providing documentation, cataloging, metadata, and access to the digitized SoundCloud recordings, but it's not clear what MXM's relationship is or could be with 
cultural heritage institutions or sound preservation professional organizations such as AMIA and IASA and the Repository of Recorded Sound.

Beyond preserving the mixtape movement, MXM seeks to encourage the academic, interdisciplinary study of mixtapes. MXM has been used in Stanford's Program in Writing and Rhetoric, including the course "Freedom's Mixtape: DJing Contemporary African American Rhetorics," and has been taught in the "Pop Music as Art and Business" course at The School of the New York Times. References offered on the site include articles and scholarly papers, blogs and websites, books, and a collection of mixtape-inspired lyrics. Articles about MXM have been published in the Art Journal, English Journal, the International Journal of Communication, the Journal of Black Studies, and the Tennessee Law Review, among others.

A primary activity that MXM facilitates is outreach and community engagement. News reports on the project have been included in the Columbia University News, New York

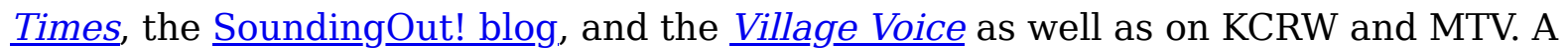
particularly interesting annual event that MXM participates in is Basement Tapes Day, hosted by Yuri Shimoda, which "provides the public with access to vintage audio playback devices so they can listen to the home recordings on open-reel tapes, cassettes, and micro-cassettes that have been sitting in their attics or basements for years." As an event staffed by volunteers from the audio preservation community (including archivists, engineers, collectors, restoration experts, and conservators), it is an opportunity for the attendees to hear and share their mixtape cultures as well as learn more about "the history of recorded sound, common deterioration issues with magnetic audio formats, and how to best store and care for their collections." 